УДК 665.6/.7+661.715.3

\title{
Extraction Octene-1 and Decene-1 \\ from C8+ Fraction by Production \\ of Linear Alpha-Olefins
}

Roman A. Vaganov, Nina V. Deryagina and Fedor A. Buryukin*

Siberian Federal University

79 Svobodny, Krasnoyarsk, 660041, Russia

Received 08.07.2015, received in revised form 21.08.2015, accepted 30.08.2015

\begin{abstract}
Modeling of the process of extraction of octene-1 and decene-1 from C8+ fraction of a cube of a column of removal of an octane by production of linear alpha-olefins for 3 versions of technological schemes is executed. Results of research include an assessment of quality of the received fractions containing octene-1 and decene-1, as well as recommendations for the direction of their further processing.
\end{abstract}

Keywords: linear alpha olefins, octene-1, decene-1, modeling, superaccurate rectification, extractive rectification.

DOI: $10.17516 / 1998-2836-2015-8-3-327-335$.

(C) Siberian Federal University. All rights reserved

* Corresponding author E-mail address: vaganov.roman@mail.ru 


\title{
Извлечение октена-1 и децена-1 \\ из фракции С8+ при производстве \\ линейных альфа-олефинов
}

\author{
Р.А. Ваганов, \\ Н.В. Дерягина, Ф.А. Бурюкин \\ Сибирский федеральный университет \\ Россия, 660041, Красноярск, пр. Свободный, 79
}

Выполнено моделирование процесса извлечения октена-1 и децена-1 из фракции С8+ куба колонны удаления октана при производстве линейных а-олефинов для трех вариантов технологических схем. Результаты исследования включают оценку качества получаемых фракиий, содержащих октен-1 и децен-1, а также рекомендации по направлению их дальнейтей переработки.

Ключевые слова: линейные альфа-олефины, октен-1, децен-1, моделирование, сверхчеткая ректификаичия, экстрактивная ректификаичия.

\section{Введение}

Алкены один из наиболее важных классов углеводородов, используемых в качестве сырья нефтехимической промышленности. Линейные $\alpha$-олефины - неразветвленные алкены с двойной связью, расположенной на конце цепи, - образуют важный подкласс непредельных углеводородов.

Линейные $\alpha$-олефины, имеющие от 4 до 20 атомов углерода, являются основным сырьем для производства поверхностно-активных веществ, технических синтетических моющих средств. Алкены с непредельной связью у крайнего атома углерода используются как прекурсоры для получения термостойких полимеров и сомономеров для получения полиолефинов. На базе высших олефинов получают такие ценные продукты, как пластификаторы, поверхностноактивные вещества с высокой биоразлагаемостью, продукты окисления, применяемые для органического синтеза, и др.

Одним из важнейших направлений использования $\alpha$-олефинов и олигомеров на их основе признано производство синтетических смазочных масел моторных, компрессорных, трансмиссионных и др. В настоящее время усиливается потребность в производстве синтетических базовых компонентов масел, удовлетворяющих технологическим требованиям по температуре застывания, вспышке и вязкости. Наиболее рациональным решением проблемы получения смазочных масел стало применение синтетических масел, из которых наиболее эффективными признаны поли- $\alpha$-олефиновые масла (далее ПАОМ), получаемые полимеризацией $\alpha$-олефинов. На практике реальный круг $\alpha$-олефинов, вовлекаемых в синтез ПАОМ, значительно ограничен, поскольку достижение необходимого сочетания важнейших свойств масел, таких как вязкостно-температурные характеристики, низкотемпературная реология, стабильность при 
высоких температурах, требует применения ограниченного числа индивидуальных $\alpha$-олефинов или их технических смесей. Вовлечение в синтез масел олефинов с двойной связью приводит к резкому падению их индекса вязкости. Следует отметить, что для всех способов получения

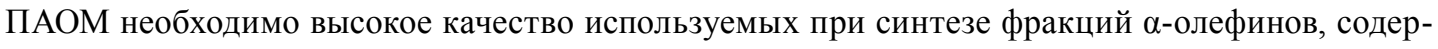
жащих октен-1 и децен-1.

Существует несколько промышленных процессов для производства октена-1 и децена-1:

- фракционная перегонка из смеси высших олефинов в процессах неселективной олигомеризации этилена;

- синтез Фишера-Тропша с последующим извлечением октена-1 из продуктового потока;

- каталитическая селективная тетрамеризация этилена;

- дегидратация спиртов;

- каталитическая тепломеризация бутадиена;

- гидроформилирование гептена-1.

Ввиду того что этилен является легкодоступным сырьем, наибольшее промышленное применение для производства $\alpha$-олефинов получил процесс олигомеризации. Необходимо отметить, что олигомеризация этилена приводит к образованию олефинов исключительно с четным числом атомов углерода, которые имеют наибольшую ценность с точки зрения коммерческого применения. На долю процесса низкотемпературной статистической олигомеризации этилена с использованием металлорганических комплексных катализаторов, содержащих титан, цирконий, палладий, железо или хром, приходится до 90 \% мирового производства $\alpha$-олефинов. Наиболее востребован в настоящее время и в перспективе каталитический процесс селективной олигомеризации этилена с образованием октена-1 (или смеси гексена-1 с октеном-1) с использованием металлокомплексных катализаторов.

Однако на отечественном рынке $\alpha$-олефинов в товарном виде октен-1 и децен-1 практически не представлены, рынок $\alpha$-олефинов в России не развит, а поставки из-за рубежа октена-1 и децена-1 нерегулярны. В 2013 г. объем рынка децена-1 составил 1,4 т и был полностью представлен импортной продукцией, при этом импорт $\alpha$-олефинов нерегулярен, а поставки октена-1 в чистом виде вообще отсутствует.

На наш взгляд, актуально определение способа извлечения октена-1 и децена-1 из фракций непредельных углеводородов $\mathrm{C}_{8}$ и $\mathrm{C}_{10}$, которые присутствуют в продуктах нефтехимического синтеза.

Результаты патентного поиска показали, что известных технических решений раздельного извлечения октена-1 и децена-1 из продукции нефтехимического синтеза не существует. При дальнейшем анализе релевантных документов, в которых смесь углеводородов рассмотрена в более широком аспекте как продукт вторичной переработки нефти, выявлены технические решения, включающие технологии вторичной переработки нефти и содержащие способы извлечения октена-1, децена-1 и других линейных $\alpha$-олефинов, а также их изомеров из смесей углеводородов.

Определены следующие технологические (в некоторых случаях лабораторные) способы, используемые для извлечения октена-1 и децена-1 из смеси углеводородов:

- ректификация; 
- экстракция, в том числе азеотропная ректификация;

- этерификация;

- аддуктообразование;

- адсорбция.

\section{Цель работы}

Целью данной работы является определение способов извлечения октена-1 и децена-1, образующихся в качестве побочных продуктов во фракции $\mathrm{C}_{8+}$ в кубе колонны удаления октана при производстве линейных $\alpha$-олефинов, а также оценка эффективности предложенных способов.

\section{Материалы, методика и оборудование для исследований}

Объект исследования технология AlphaHexol ${ }^{\mathrm{TM}}$. Технология AlphaHexol ${ }^{\mathrm{TM}}$ разработана международной компанией IFP Group Technologies AXENS. Данная технология используется при проектировании нефтехимического комплекса в Приморском крае (ЗАО «ВНХК»). Однако в технологии AlphaHexolтм отсутствует система выделения ценных октена-1 и децена-1 из кубового остатка ректификационной колонны удаления октана при производстве линейных $\alpha$-олефинов.

Для определения возможных способов извлечения октена-1 и децена-1 из фракции $\mathrm{C}_{8+}$ куба колонны удаления октана при производстве линейных $\alpha$-олефинов использована система моделирования AspenONE. Система имеет графический интерфейс, позволяющий формировать схемы непосредственно на экране компьютера, выбирая элементы из списка и соединяя их в определенном порядке. При расчете схемы взаимосвязанных аппаратов последовательность расчета элементов определяется автоматически (или может быть задана пользователем). При наличии рециклов создается итерационная схема, в которой рецикловые потоки разрываются и создается последовательность сходящихся оценочных значений. Эти значения получаются замещением величин, рассчитанных при предыдущем просчете схемы (метод простого замещения), или путем применения специальных методов ускорения расчета рециклов Вегштейна (Wegstein) и Бройдена (Broyden).

Наибольшей сложностью при извлечении необходимых $\alpha$-олефинов в технологии AlphaHexolтм является то, что кубовый поток колонны отделения октана представляет собой сложную смесь изомерных углеводородов.

Состав кубового потока колонны отделения октана (табл. 1) принят на основании исходных данных, предоставленных ЗАО «ВНХК» по договору оказания инжиниринговых услуг.

Из анализа этих данных по составу кубового потока следует, что помимо октена-1 и децена-1 в кубовом потоке присутствуют их цис-, транс- и разветвлённые изомеры, а также олефины с кратной связью внутри углеродного скелета, которые трудно отделить от целевых $\alpha$-олефинов из-за близких температур кипения и идентичных химических свойств.

Таким образом, для извлечения октена-1 и децена-1 из кубового потока колонны отделения октана необходимо:

- выделить из широкой фракции $\mathrm{C}_{8+}$ более узкие фракции $\mathrm{C}_{8}$ и $\mathrm{C}_{10}$;

$$
-330-
$$


Таблица 1. Состав фракции $\mathrm{C}_{8+}$ куба колонны удаления октана

\begin{tabular}{|l|c|c|c|}
\hline \multicolumn{1}{|c|}{ Компонент } & $\begin{array}{c}\text { Содержание, } \\
\text { \% масс. }\end{array}$ & Расход, кг/ч & $\begin{array}{c}\text { Молярная масса, } \\
\text { кг/кмоль }\end{array}$ \\
\hline Гексен-1 & 0,01 & 0,02 & 84 \\
Циклогексан & 5,06 & 11,99 & 100 \\
Гептан & 0,06 & 0,14 & 98 \\
Метилциклогексан & 0,3 & 0,71 & 130 \\
Этилгексанол & 0,08 & 0,19 & 114 \\
Октан & 1,9 & 4,50 & 112 \\
Октены & 14,75 & 34,96 & 112 \\
в т.ч. октен-1 & 4,73 & 11,21 & 144 \\
Деканы & 0,66 & 1,56 & 142 \\
Децены & 72,13 & 170,95 & 142 \\
в т.ч. децен-1 & 4,73 & 11,21 & 168 \\
С & $5,05 \%$ додецен-1) & 11,97 & \\
Итого & 100 & 237 & 8 \\
\hline
\end{tabular}

- извлечь из смеси изомеров $\mathrm{C}_{8}$ и $\mathrm{C}_{10}$ необходимые $\alpha$-олефины.

На основании исходных данных по составу фракции $\mathrm{C}_{8+}$ нами предлагаются три варианта процесса извлечения октена-1 и децена-1 из куба колонны отделения октана:

1-й вариант извлечение октена-1 и децена-1 из фракции $\mathrm{C}_{8+}$ с помощью процесса сверхчёткой ректификации.

Для разделения исследуемой смеси углеводородов на фракции $\mathrm{C}_{6}-\mathrm{C}_{7}, \mathrm{C}_{8}, \mathrm{C}_{9}, \mathrm{C}_{10}$ и $\mathrm{C}_{11+}$ необходимо использовать как минимум четыре последовательно работающие ректификационные колонны. Разделение близкокипящих углеводородов производится сверхчеткой ректификацией, которая требует большого числа контактных тарелок (70-100 и более) и высоких значений флегмового числа. Принципиальная схема сверхчёткой ректификации фракции $\mathrm{C}_{8+}$ представлена на рис. 1.

2-й вариант извлечение октена-1 и децена-1 из фракции $\mathrm{C}_{8^{+}}$с помощью процесса экстрактивной ректификации в присутствии третбутил ацетата.

Способ заключается в сверхчеткой ректификации с применением азеотропной и экстрактивной ректификации для повышения селективности извлечения октена-1 в присутствии третбутил ацетата, подаваемого в 1-ю колонну. Принципиальная схема процесса извлечения октена-1 и децена-1 с помощью экстрактивной ректификации в присутствии третбутил ацетата изображена на рис. 2.

3-й вариант извлечение октена-1 и децена-1 из фракции $\mathrm{C}_{8_{+}}$с помощью процесса экстрактивной ректификации в присутствии этилбутирата.

Процесс основан на азеотропной и экстрактивной ректификации в присутствии этилбутирата, повышающей селективность извлечения децена-1. Принципиальная схема экстрактивной ректификации в присутствии этилбутирата, подаваемого в 3-ю колонну, представлена на рис. 3.

$$
-331-
$$




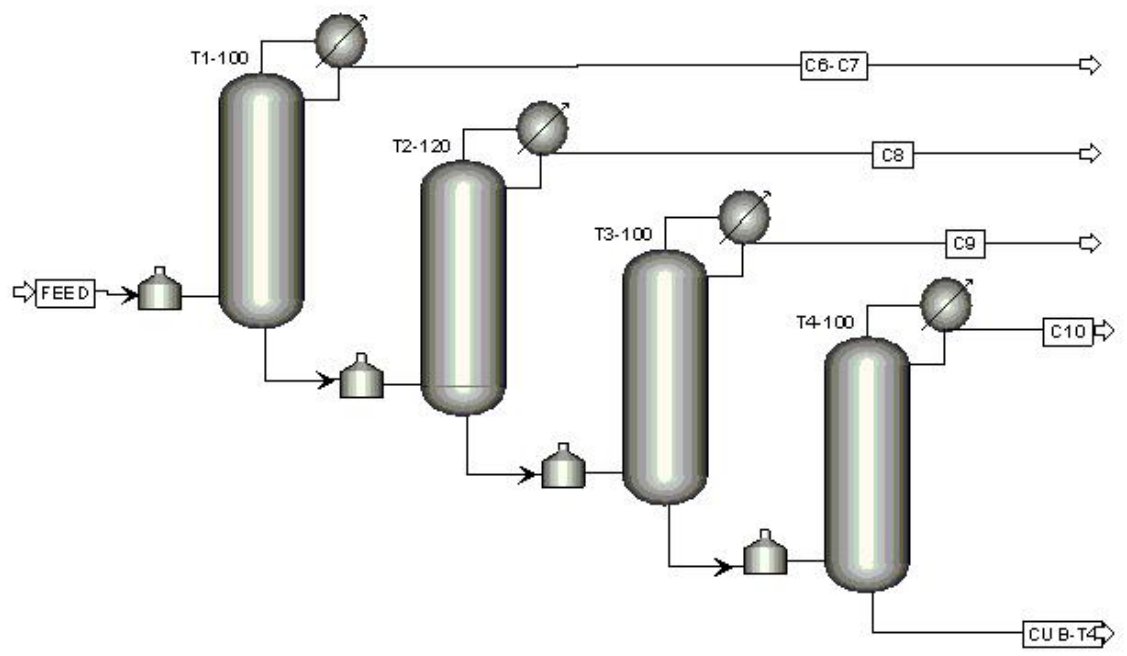

Рис. 1. Принципиальная схема сверхчёткой ректификации фракции $\mathrm{C}_{8+}$ : T1-100, Т2-120, Т3-100, Т4-100 ректификационные колонны, Feed подача сырья, C6-C7, C8, C9, C10 продуктовые фракции, CUB T4 кубовый поток ректификационной колонны 4

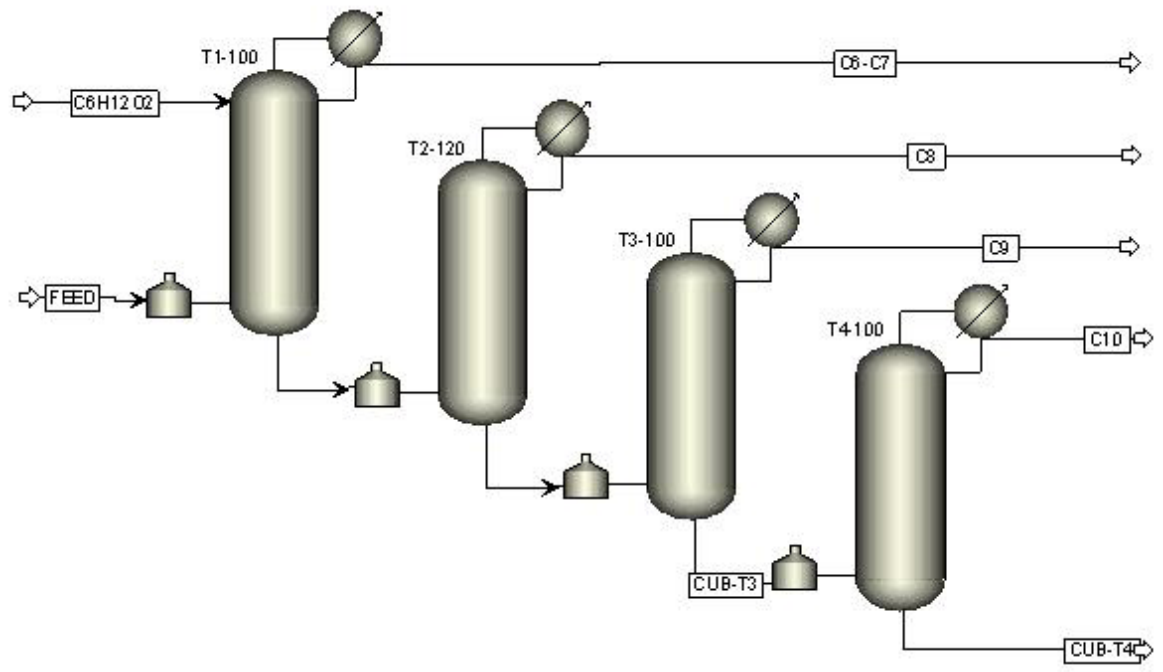

Рис. 2. Принципиальная схема экстрактивной ректификации в присутствии третбутил ацетата: T1-100, Т2-120, Т3-100, Т4-100 ректификационные колонны, Feed подача сырья, C6-C7, C8, C9, C10 продуктовые фракции, CUB T3, CUB T4 кубовые потоки ректификационных колонн 3 и 4, C6H12O2 третбутил ацетат

\section{Результаты исследования}

В результате моделирования процесса извлечения октена-1 и децена-1 в системе моделирования AspenONE получены материальные балансы процессов для всех предложенных вариантов. В качестве критерия оптимизации процесса извлечения $\alpha$-олефинов было выбрано содержание октена-1 и децена-1 в потоках $\mathrm{C}_{8}$ и $\mathrm{C}_{10}$ соответственно. В качестве управляющих параметров использованы такие характеристики, как номер питающей тарелки, количество 


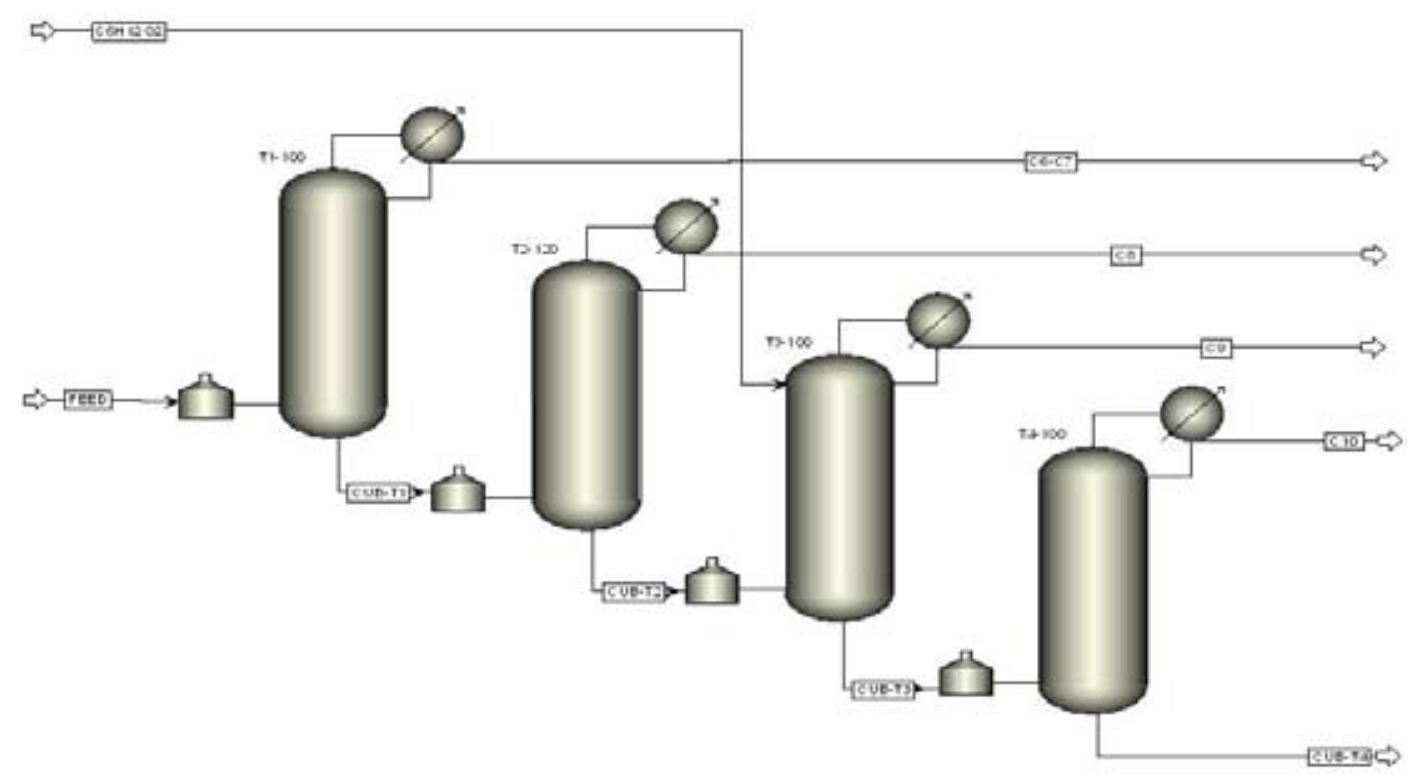

Рис. 3. Принципиальная схема экстрактивной ректификации в присутствии этилбутирата: Т1-100, Т2120, T3-100, T4-100 ректификационные колонны, Feed подача сырья, C6-C7, C8, C9, С10 продуктовые фракции, CUB T1, CUB T2, CUB T3, CUB T4 кубовые потоки ректификационных колонн 1, 2, 3 и 4, С6Н12О2 этилбутират

теоретических тарелок, перепад давления в колоннах, степень отбора продукта, температура в колонне и потоков сырья.

Из анализа материального баланса процессов извлечения октена-1 и децена-1 из фракции $\mathrm{C}_{8+}$ следует, что фракция $\mathrm{C}_{6}-\mathrm{C}_{7}$ практически на $50 \%$ состоит из циклогексана, оставшиеся $50 \%$ представлены смесью различных изомеров от $\mathrm{C}_{6}$ до $\mathrm{C}_{8}$ для всех перечисленных выше вариантов.

Результаты определения выхода целевых $\alpha$-олефинов из сырья и соответствующих фракций $\mathrm{C}_{8}$ и $\mathrm{C}_{10}$ даны в табл. 2.

Четкость отделения фракции $\mathrm{C}_{8}$ от углеводородов с большим и меньшим количеством атомов составляет $100 \%$. Фракция $\mathrm{C}_{9}$ большей частью состоит из 2-метилнонена-1 и 8-метилнонена, 55 и $20 \%$ соответственно, оставшаяся часть состоит из примесей различных углеводородов от $\mathrm{C}_{8}$ до $\mathrm{C}_{10}$.

Расчет показал, что в продуктовом потоке фракции $\mathrm{C}_{8}$ помимо октена-1 присутствуют такие углеводороды, как 2-этил-гексен-1, 2-метил-гептен-1, цис-4-октен и цис-3-октен, остальные углеводороды $\mathrm{C}_{8}$ представлены в небольшом количестве. Фракция $\mathrm{C}_{10}$ наряду с деценом-1 содержит 2-метил-1-нонен, 8-метил-1-нонен, транс-2-децен и цис-2-децен.

В кубовом потоке колонны 4 в небольших количествах (не более 10 \%) содержатся ценные линейные $\alpha$-олефины децен-1 и додецен-1, но большую часть фракции составляет смесь трансдецена-2 и цис-децена-2.

Результаты сравнения выхода целевых $\alpha$-олефинов из сырья и соответствующих фракций $\mathrm{C}_{8}$ и $\mathrm{C}_{10}$ (табл. 2) показывают, что процесс сверхчёткой ректификации обладает низкой селек- 
Таблица 2. Выход октена-1 и децена-1 из кубового потока выделения октана и из соответствующих фракций $\mathrm{C}_{8}$ и $\mathrm{C}_{10}$

\begin{tabular}{|c|c|c|c|c|}
\hline \multirow{3}{*}{$\begin{array}{c}\text { Процессы выделения октена-1 } \\
\text { и децена-1 }\end{array}$} & \multicolumn{4}{|c|}{ Выход, \% масс. } \\
\hline & \multicolumn{2}{|c|}{ Октен-1 } & \multicolumn{2}{|c|}{ Децен-1 } \\
\hline & $\begin{array}{c}\text { Кубовый } \\
\text { поток колонны } \\
\text { выделения } \mathrm{C}_{8}\end{array}$ & Фракция $\mathrm{C}_{8}$ & $\begin{array}{c}\text { Кубовый } \\
\text { поток колонны } \\
\text { выделения } \mathrm{C}_{8}\end{array}$ & Фракция $\mathrm{C}_{10}$ \\
\hline Процесс сверхчеткой ректификации & 80 & 68 & 66 & 21 \\
\hline $\begin{array}{l}\text { Процесс экстрактивной ректификации } \\
\text { в присутствии третбутил ацетата }\end{array}$ & 82 & 71 & 66 & 21 \\
\hline $\begin{array}{l}\text { Процесс экстрактивной ректификации } \\
\text { в присутствии этилбутирата }\end{array}$ & 79 & 68 & 62,5 & 20 \\
\hline
\end{tabular}

тивностью, которая обусловлена сложным углеводородным составом кубового потока колонны отделения октана. Многие изомеры имеют идентичные температуры кипения либо образуют азеотропные смеси. Однако следует отметить достаточно хорошую четкость выделения целевых фракций $\mathrm{C}_{8}$ и $\mathrm{C}_{10}$ в данном способе.

Использование третбутил ацетата повышает селективность ректификации в отношении октена-1. Об этом свидетельствует тот факт, что содержание основных примесей во фракции $\mathrm{C}_{8}$, таких как 2-этил-гексен-1, 2-метил-гептен-1, цис-4-октен и цис-3-октен, значительно снизилось (табл. 2). Третбутил ацетат обладает селективностью по отношению к октену-1, и на извлечение децена-1 его применение предсказуемо не повлияло.

В целом можно сделать вывод, что технология экстрактивной ректификации для выделения октена-1 и децена-1 более эффективна, чем простая ректификация.

Вовлечение в процесс ректификации этилбутирата практически не изменило соотношения содержания основных углеводородов во фракции $\mathrm{C}_{9}$. Около 75 \% углеводородов приходится на 2-метилнонен-1 и 8-метилнонен, $25 \%$ на различные изомеры углеводородов от $\mathrm{C}_{8}$ до $\mathrm{C}_{10}$. При этом в продуктовом потоке $\mathrm{C}_{10}$ выход целевого децена-1 уменьшился до $62,5 \%$ от общего количества децена-1 в исходном сырье. Степень отделения фракции углеводородов $\mathrm{C}_{10}$ практически полная, содержание в ней децена-1 уменьшилось до $20 \%$. Фракция $\mathrm{C}_{10}$ наряду с деценом-1 также содержит 2-метил-1-нонен, 8-метил-1-нонен, транс-2-децен и цис-2-децен.

Таким образом, расчет с использованием моделирующего комплекса AspenONE, который с высокой вероятностью прогнозирует основные физико-химические свойства углеводородов и их взаимодействие в массобменных процессах, показал низкую эффективность применения этилбутирата в качестве экстрагента для децена-1.

\section{Выводы}

Таким образом, из предложенных трех способов извлечения октена-1 и децена-1 из кубового потока колонны отделения октана в технологии AlphaHexol ${ }^{\mathrm{TM}}$ по технологическому оформлению и выходу октена-1 и децена-1 наиболее перспективными являются варианты сверхчёткой ректификации и экстрактивной ректификации в присутствии третбутил ацетата. 
Однако предложенные варианты извлечения октена-1 и децена-1 из кубового потока колонны отделения октана с помощью сверхчеткой ректификации и экстрактивной ректификации в присутствии третбутил ацетата не позволяют получать продуктовые фракции, которые могут выпускаться в виде товарной продукции без дополнительной доочистки, так как в обоих процессах содержание октена-1 во фракции $\mathrm{C}_{8}$ не превышает 71 \%, а содержание децена-1 во фракции $\mathrm{C}_{10}$ не более $21 \%$. Очевидно, что для дальнейшего использования $\alpha$-олефинов необходимо получать фракции с максимально возможным содержанием целевых компонентов. Для увеличения степени чистоты линейных $\alpha$-олефинов в фракциях $\mathrm{C}_{8}$ и $\mathrm{C}_{10}$ необходимы дальнейшие исследования процесса экстрактивной ректификации и подбор экстрагентов, обладающих лучшей селективностью к октену-1 и децену-1.

\section{Список литературы}

1. Харлампиди Х.Э., Чиркунов Э.В., Плаксунов Т.К., Ефанова Э.А., Лаптев Т.Ю. Синтез и применение продуктов на основе высших олефинов // Продукты нефтехимического синте3a. 2012. C. 142-150. [Harlampidi H.E., Chirkunov E.V., Plaksunov T.K., Efanova E.A., Laptev T.Yu. Synthesis and application of products on the basis of the highest olefins//Products of petrochemical synthesis. 2012. P. 142-150. (In Russ.)]

2. Белов Г.П., Матковский П.Е. Технологии получения высших линейных $\alpha$-олефинов // Нефтехимия. 2010. Т. 50, № 4. С. 296-302.[ Belov G. P., Matkovsky P.E. Technologies of receiving the highest linear alpfa- olefins//Petrochemistry. 2010. T. 50, № 4. P. 296-302. (In Russ.)]

3. Цветков О.Н., Школьников В.М., Богданов Ш.К., Топорищева Р.И. // Химия и технология топлив и масел. 1982. № 10. С. 42-44. [Tsvetkov O. N., Shkolnikov V. M., Bogdanov Sh. K., Toporischeva R. I. // Chemistry and technology of fuels and oils. 1982. № 10. P. 42-44]

4. Фудзивара Н. // Дзюнкацу цисин. 1982. т. 181.- с. 27-28 / Перевод ВЦП № Е-42518.-1984. [Fujiwara N. // Dzyunkatsu tsisin. 1982 m. From 181. 27-28 / Translation TDC number E-1984 42518.1984.]

5. Баширов Р.Ф., Муртазин Р.Г., Хасанов Р.Г., Сагитов Р.Р., Ахметов С.А. Моделирование равновесного состава продуктов пиролиза углеводородов и прогнозирование выхода суммы олефинов // Нефтепереработка и нефтехимия. 2008. № 4-5. C. 112-115. [Bashirov R. F., Murtazin R. G., Khasanov R. G., Sagitov R. R., Akhmetov S. A. Modeling of equilibrium structure of products of pyrolysis of hydrocarbons and forecasting of an exit of the sum of olefins//Oil processing and petrochemistry. 2008. № 4-5. P. 112-115. (In Russ.)]

6. Ахмедьянов М.С., Ахмедьянова Р.А., Лиакумович А.Г., Гнездилов О.И., Урядов В.Г. Очистка октена-1 от винилиденовых соединений реакцией олигомеризации // Бутлеровские сообщения. 2013. T. 33. № 1. C. 87-92. [Akhmedyanov M. S., Akhmedyanova R. A., Liakumovich A.G., Gnezdilov O. I., Uryadov V. G. Purification of octene-1 from vinylidene compounds by reaction of oligomerization //Butlerovsky messages. 2013. T. 33. № 1. P. 87-92. (In Russ.)] 